\title{
HPTLC Fingerprint Analysis of Plant Staminal Cells Products
}

\section{Marcello Nicoletti* and Chiara Toniolo}

Department of Environmental Biology, Quality Control Center, University Sapienza of Rome, P.le A. Moro 500185, Rome, Italy

\begin{abstract}
Utilization of natural products is radically changing. Changes were mainly due to the outcome in the market of a plethora of new food supplements, and in particular those generally named botanicals for their common plant origin The validation of these novel products needs powerful analytical devices tailored for the study of herbal extracts in order to assess composition and face their natural complexity as a resource. The last item is important and crucial for the capacity and utility of the analytical results that means that each product should be analyzed with the right approach. Having in mind these arguments, we selected HPTLC as useful tool for the analysis of products based on plant staminal (stem) cells. Nowadays these products, generally named bud-derivatives, are waiting scientific validation to obtain their own place into food supplements regulation, after gained that in the market.
\end{abstract}

Our analyses, based on HPTLC fingerprints, were able to show bud-derivatives complex compositions that resulted very similar, but also in part different, to those of the corresponding leaf hydro-alcoholic extract.

Keywords: HPTLC; Food supplements; Botanicals; Bud-therapy

\section{Introduction}

Actually, much expectation concerns human stem cell and their possible applications in many fields, first the medical one. It is clear that a long way still must be done, considering also the ethical implications. Nowadays, researcher's attention is focused on two main arguments: understand the principles of staminal cells derivation in embryonic stem (ES) and in induced pluripotent stem (iPS). Waiting that answers overcome questions and doubles, some easier applications started in the plant field. Utilizations were focused on meristematic tissues that can be considered as staminal cells in plants. Meristems are constituted by totipotent cells mainly present in apical parts, although also the parenchymal cells are able to work similarly if necessary. Their function consists in the generation of new cells that will differentiate according to their position and functionality. Meristems are divided into primary, mainly derived from the embryo and responsible of the tissue architecture of herbs, and secondary, from which derive the production of plant secondary structure, when present, including most of wood and of additional functional parts. The main difference with animal and human staminal cells is that meristems are active during all steps of plant life and scattered in several parts of the plant body [1-3].

New food supplements account for a multimillion market, and in particular those generally named botanicals for their common plant origin [4-6]. They are well accepted by consumers and based on the contaminated target between medical and dietary/nutritional expectations. Waiting for the results of the claims debate [7,8], attention can be focused on security, in particular on the assessment of the herbal composition, also in consideration of the important cases of adulteration by synthetic drugs to enhance activity [9-12].

The validation of these novel products need powerful analytical devices tailored for the study of herbal extracts in order to face their natural complexity in composition as a resource. Among botanicals, a special attention must be deserved to the most innovative products, like those utilized in bud-therapy. Bud-therapy possesses a special appeal. Probably, everything starts from spring revival or the miracle of a new life born from plant vitality, experimented by everyone in the simple act of planting a little piece of woody branch into the ground, just waiting for the spring of a splendid rose or a monumental ginkgo. The expectation is that the same vitality could be in some way captured and technologically transferred.
The therapeutic use of buds or other young and developing vegetal parts cannot be considered a new entry. Several animals when sick use to look for buds for recovering. In Ayurvedic and Chinese Traditional Medicine they have an important place in the therapeutic tools. Also in the Materia Medica, we can find several important references, from the use of poplar buds by Galeno and Nicolas De Hyrepse, up to Paracelso. The general idea was to profit of the renewing force of growing or new born parts of the plant. This concern was on the basis of the modern medical approaches, that started in ' 50 by the medical doctor and botanist Pal Henry [13] and nowadays reported in the new uses approach based on botanicals and named in several ways, i.e. bud-, meristematic-, embrio-, phytoembrio-, blasto-therapy among others. For simplicity, we will adopt the term of bud-therapy, referring to a modern non-conventional medical therapy using plant raw materials rich in meristemic cells to obtain bud-derivatives products. Although increasing in public concern and request, bud-therapy is still in search of its proper definition, recognition, validation and normative acceptance.

The true epistemic tissue is very narrow, generally monolayer, and therefore very difficult to be separated from neighbouring cells, also by expert researchers in plant histology. Into a bud there is a mix of cells at different stages of differentiation, including the slide producing other cells. In bud-therapy, for production of bud-derivatives the raw material is restricted to fresh plant tissues or juvenile parts: buds, shoots, young roots and branches and their bark, as well as any other tissues considered in some way containing meristemic or developing cells. In some cases for the embryo presence also seeds and fruits are included.

Extracts are generally obtained by the use of a mix of ethanol/

*Corresponding author: Marcello Nicoletti, Department of Environmental Biology, Quality Control Center, University Sapienza of Rome, P.le A. Moro 500185, Rome, Italy, E-mail: marcello.nicoletti@uniroma1.it

Received September 20, 2012; Accepted October 26, 2012; Published October 29, 2012

Citation: Nicoletti M, Toniolo C (2012) HPTLC Fingerprint Analysis of Plant Staminal Cells Products. J Chromat Separation Techniq 3:148. doi:10.4172/21577064.1000148

Copyright: (c) 2012 Nicoletti M, et al. This is an open-access article distributed under the terms of the Creative Commons Attribution License, which permits unrestricted use, distribution, and reproduction in any medium, provided the original author and source are credited. 
glycerine, followed by a possible dilution in accordance with the homeopathic method, as reported in the French Pharmacopoeia [13], where they were introduced from 1965. Two main products are therefore obtained: the GM (Glyceric Macerate) and it's 10 times dilution, according the homeopathic method using a mixture of water/ ethanol/glycerine 20:30:50 in order to obtain the solution $1 \mathrm{DH}$. In consideration of these characteristics and of the dilution method, they are associated to the homeopathy. These products have so far a restricted market, being present mainly in France, Italy and Germany, but their importance is in progress, including in the cosmetic field. The basic idea is that, for their special nature, they should help tissues to remain young and flexible.

About their chemical composition, the general consideration was that they mainly should contain hormones, some proteins, minerals, vitamins and water, whereas production of specific and secondary metabolites should be delayed to the differentiation step. The absence of active constituents was the main argument declared by denigrators of bud-derivatives, to evidence their uselessness and claim their return from the market.

\section{Material and Methods}

\section{Chemicals, reagents, materials and solutions}

Methanol for analysis and other HPLC grade solvents were purchased from Sigma-Aldrich (Milan, Italy) and Carlo Erba (Milan, Italy) Samples. Detailed information, i.e. producers, production conditions, storage method, etc. can be obtained by directly asking the authors. Extracts utilised as mono-herbal standards were hydro alcoholic $95^{\circ}$ extracts obtained from the market or by lab extraction of identified herbal raw materials $(5 \mathrm{mg} / 10 \mathrm{~mL})$, the last also used as reference to confirm the identities of the marketed ones.

\section{Chromatographic equipment}

The HPTLC system (CAMAG, Muttenz, Switzerland) consisted of (i) Linomat 5 sample applicator using $100 \mu \mathrm{L}$ syringes and connected to a nitrogen tank; (ii) chamber ADC 2 containing twin trough chamber $20 \times 10 \mathrm{~cm}$; (iii) Camag TLC visualizer; (iv) Camag TLC scanner 3 linked to winCATS software

\section{Sample preparation and application}

The dried extracts of the analysed samples were weighted and dissolved in methanol $(6 \mathrm{mg} / \mathrm{mL})$.

\section{HPTLC plates}

Normal phase glass plates $20 \times 10 \mathrm{~cm}$ (Merck, Darmstadt, Germany) with glass-backed layers silica gel 60 ( $2 \mu \mathrm{m}$ thickness). Before use, plates were prewashed with methanol and dried for $3 \mathrm{~min}$ at $100^{\circ} \mathrm{C}$. Filtered solutions were applied with nitrogen flow. The operating conditions were: syringe delivery speed, $10 \mathrm{~s}^{-1} \mathrm{~L}^{-1}\left(100 \mathrm{~nL} \mathrm{~s}{ }^{-1}\right)$; injection volume, 3 $\mu \mathrm{L}$; band width, $8 \mathrm{~mm}$; distance from bottom, $15 \mathrm{~mm}$.

\section{Development}

The HPTLC plates were developed in the automatic and reproducibly developing chamber ADC 2, saturated with the same mobile phase dichloromethane:methanol 9:1 (v/v) for $20 \mathrm{~min}$ at room temperature. The developing solvents (i.e. type of solvents and ratios) were carefully optimized before the analyses. The length of the chromatogram run was $70 \mathrm{~mm}$ from the point of application.

\section{Derivatization reagents and inspection}

The developed layers were allowed to dry on Camag TLC Plate eater III for $5 \mathrm{~min}$ and then derivatised with anhisaldehyde $(1.5 \mathrm{ml}$ p-anisaldehyde, $2.5 \mathrm{ml} \mathrm{H} 2 \mathrm{SO} 4,1 \mathrm{ml} \mathrm{AcOH}$ in $37 \mathrm{ml} \mathrm{EtOH}$ ) and then treated on Camag TLC Plate eater III for $5 \mathrm{~min}$ at $110^{\circ} \mathrm{C}$. All treated plates were then inspected under a UV light at 254 or $366 \mathrm{~nm}$ or under white light upper and lower (WRT), respectively, at a Camag TLC visualizer, before and after derivatization.

\section{Stability}

Sample solution of the extracts were prepared and stored at room temperature for 3 days and then applied on the same HPTLC plated and the chromatogram evaluated for additional band. Similarly band stability was checked by keeping the resolved peaks and inspecting at intervals of 12, 24 and $49 \mathrm{~h}$.

\section{Validation}

Overlapping of bands is a typical analytical challenge for complex mixtures like multi-ingredient products. HPTLC allowed a good separation and visualization of the constituents. Sample solutions of the extracts were found to be stable at $4^{\circ} \mathrm{C}$ for at least 1 month and for at least 3 days on the HPTLC plates. Repeatability was determined by running a minimum of three analyses. RF values for main selected compounds varied less than $0.02 \%$. The effects of small changes in the mobile phase composition, mobile phase volume, and duration of saturation were minute and reduced by the direct comparison; On the contrary, the results were critically dependent on prewashing of HPTLC plates with methanol.

\section{Results}

\section{Towards validation}

The misunderstanding coming from the relationship with homeopathic products and the meristemic nature of the raw material, leads to the common idea that these products should contain irrelevant constituents, at least some primary metabolites, few enzymes and proteins. In any case, the possibilities to demonstrate the contrary have to face the very low quantities of the secondary constituents and therefore the detection limit of the method must be very efficient. Furthermore, the analyses are complicated by the relevant presence of glycerine, covering and affecting most of the chromatograms. Another controversy concerns the real pharmacological properties of these products, generally considered like a placebo. However, if the activity is quite difficult to ascertain, the determination of the composition is another matter.

HPTLC, High Performance Thin Layer Chromatography, is the most recent evolution of planar chromatography and has been specifically tailored for analysis of natural products [14,15]. Typical product of the HPTLC is the fingerprint, as the individual chromatographic track representing, as near as possible, a mixture of organic substances $[16,17]$. Furthermore, the same plate can be visualized in several ways and individual spot quantitatively determined by densitometry. HPTLC already is adopted in modern validation of herbal drugs [18]. HPTLC fingerprints of main Chinese plant drugs extracts are reported in a special book of the Chinese Pharmacopoieas [19] and HPTLC analyses reported in US Herbal Pharmacopoeia [20]. Furthermore, the HPTLC and HPLC-DAD fingerprints have been officially recognized by World Health Organisation as methods to identify a species or its preparations by a characteristic chromatographic profile when it is not possible to identify an active principle [21]. 
Citation: Nicoletti M, Toniolo C (2012) HPTLC Fingerprint Analysis of Plant Staminal Cells Products. J Chromat Separation Techniq 3:148. doi:10.4172/2157-7064.1000148

Page 3 of 4

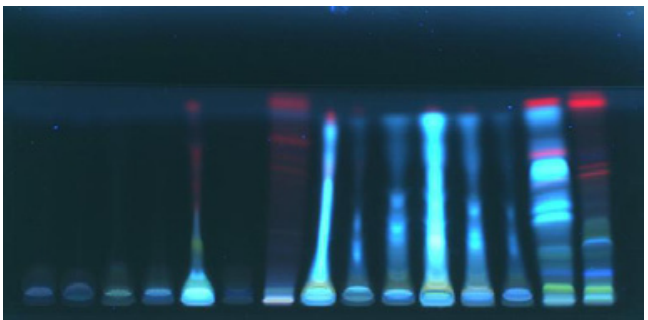

Figure 1: HPTLC analysis of bud-derivatives without any pre-treatment, evidencing the devastating effects of glycerine.

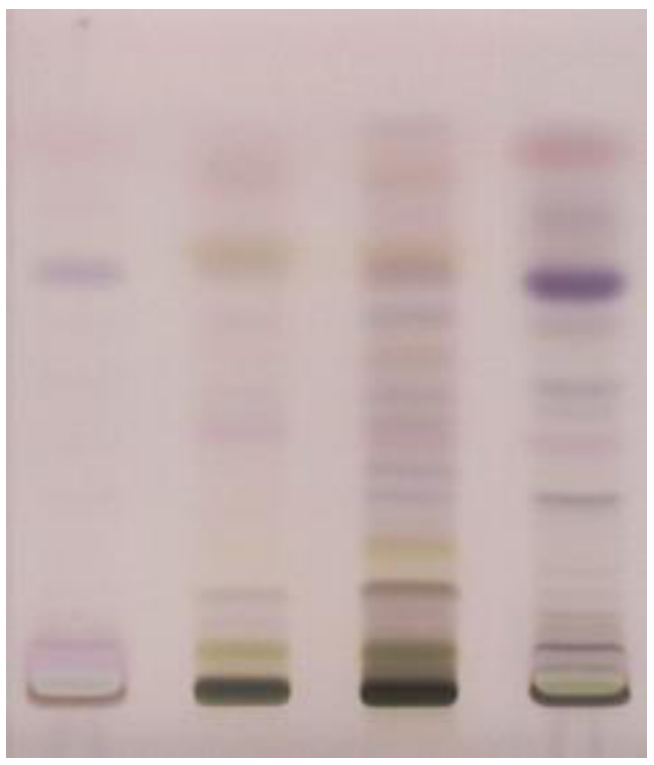

Figure 2: HPTLC analysis of bud-derivatives of rosemary. Visualization: WRT. Rosmarinus officinalis Tracks: 1 MG of young buds, 2 hydroalcholic extract of buds, 3 hydroalcholic extract of fresh leaves; 4 MG of mature buds.

\section{HPTLC fingerprints of bud derivatives}

The HPTLC fingerprint approach was applied to bus derivatives in order to reach two main goals: evidence the presence of constituents and test its possible role in the identification of the utilized raw material.

The first consideration concerns the high quantity of glycerine present in the products. As evidenced in Figure 1, glycerine can interfere highly in the chromatography, depriving the analysis of any quality and possible interpretation. On the other hand, a remove of the glycerine, partially or totally by solvent, could affect the real composition of the analyzed material. We were able to limit the interference of glycerine that was practically confined near the starting line with limited or null influence on the chromatogram, although in several cases the linearity of the spots is affected [22].

The HPTLC analyses evidenced the chemical contents of budderivatives (MG): the tracks contain spots of several secondary metabolites, in accordance with a specific fingerprint. This result was confirmed for rosemary products by the comparison of MG with the corresponding fingerprints of the hydro-alcoholic extracts (EI) of the leaves of same species (Figure 2). Also the densitometric conversion showed the same situation (Figure 3). The comparison with other mother tinctures (Figure 4) showed a relevant correspondence, allowing a botanical identification, but additional spots were generally present, confirming the peculiarity of staminal cells, as well as the peculiar extracting method, and therefore testifying for their specific use [23].

The products obtained in accordance with the French Pharmacopoeia responded better to the separation, whereas products obtained using more polar solvents presented several problems that must be solved with solutions ad hoc. The analysis of $1 \mathrm{DH}$ products was difficult (Figure 5). Albeit it is quite clear that they have the same fingerprints of MG, to obtain a clear fingerprint a higher concentration of the product should be necessary that would increase the negative influence of glycerine. Therefore, the best compromise must be found, depending from the analysed species and product.

\section{Conclusions}

Although HPLC remains the current best analytical tool for organic

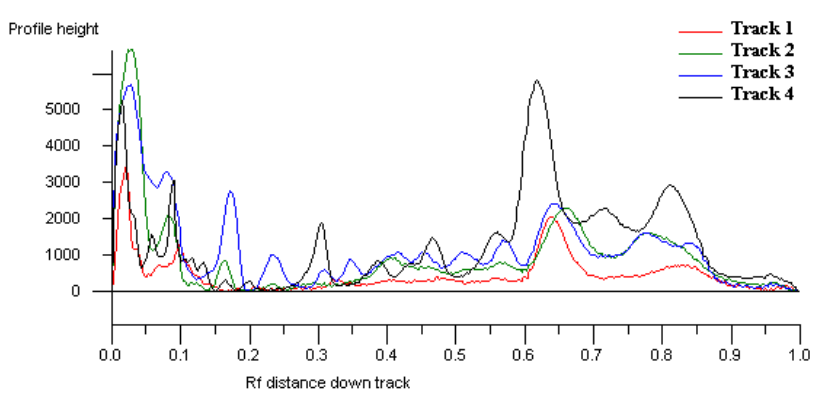

Figure 3: Densitometric profiles of tracks of Figure 2.

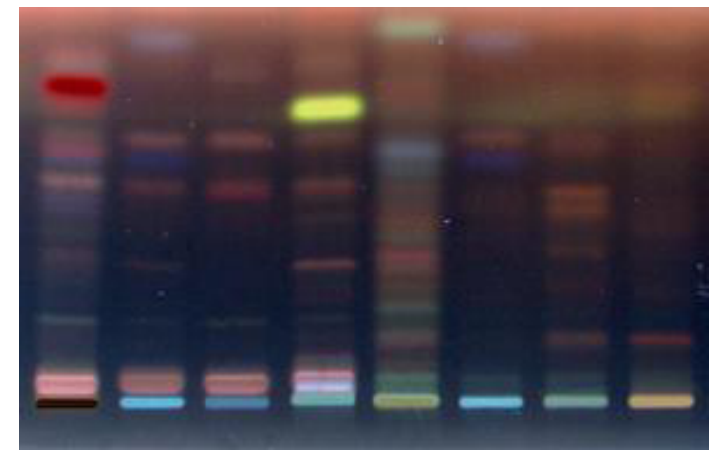

Figure 4: HPTLC analysis of bud-derivatives. Visualization: UV $366 \mathrm{~nm}$. Tracks: 1 Ribes nigrum MG, 2 Ficus carica MG, 3 Tilia tomentosa MG, 4 Rosmarinus officinalis MG, 5 Ribes nigrum El, 6 Ficus carica El, 7 Tilia tomentosa El, 8 Rosmarinus officinalis El.

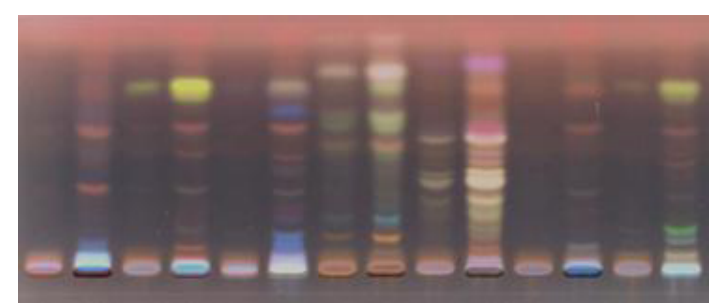

Figure 5: HPTLC analysis of bud-derivative MG and $1 \mathrm{DHs}$. Visualization: UV $366 \mathrm{~nm}$. Tracks: Aesculus hyppocastanum 1,1 DH, and 2, MG; Crataegus oxyacantha $3,1 \mathrm{DH}$, and 4, MG; Fraxinus exceksior $5,1 \mathrm{DH}$, and $6, \mathrm{MG}$; Pinus mugo 7,1 DH, and 8, MG; Alnus glutinosa, 9,1 DH, and 10, MG; 10 Rosa canina $11,1 \mathrm{DH}$, and 12, MG; Viscum album $13,1 \mathrm{DH}$, and 14, MG. 
Citation: Nicoletti M, Toniolo C (2012) HPTLC Fingerprint Analysis of Plant Staminal Cells Products. J Chromat Separation Techniq 3:148. doi:10.4172/2157-7064.1000148

substances, other instrumental possibilities have been proposed. Nowadays, HPTLC is ready to become one of the best methods for control of quality, purity, stability and identity, in one word chemical validation, of complex botanical products. Therefore, botanicals can be easily and simply compared using the fingerprint approach and presence of adulterants as well detected. Main default concerns the still high cost of instrumentation and main advantage consists into the clear and simple evidence of the understandable result typical of TLC, avoiding the limits derived by the use of too specialized analyses.

On the basis of the HPTLC analyses performed on plant staminal cells products, the following considerations can be proposed: a) HPTLC can be used to evidence the compositions of these products (MG), also in cases of complex mixtures, although low concentrations of $1 \mathrm{DH}$ can constitute a limit b) the compositions of these products can be visualized and compared with those of the hydro-alcoholic extracts; c) the fingerprints of bud-derivatives (MG) and hydro-alcoholic extract (EI) of the same plant appear similar but not equal, confirming the differences due to the different raw materials and extraction process; d) the interference of glycerine can be limited owing to its segregation near the deposition line.

Therefore, now the reported medicinal activities of bud-derivatives can be related to the secondary metabolites constituents.

\section{References}

1. Verdeil JL, Alemanno L, Niemenak N, Tranbarger TJ (2007) Pluripotent versus totipotent plant stem cells: dependence versus autonomy? Trends Plant Sci 12: $245-252$

2. Gray J (2004) Paradigms of the evolution of programmed cell death. In Gray $\mathrm{J}(\mathrm{edn})$ Programmed cell death in plants. Boca Raton FL: CRC Press 1-20.

3. Savona M, Mattioli R, Nigro S, Falasca G, Della Rovere F, et al. (2012) Two SERK genes are markers of pluripotency in Cyclamen persicum Mill. J Exp Bot 63: 471-488.

4. Nicoletti M (2012) Nutraceuticals and Botanicals: overview and perspectives. Int J Food Sci Nutr 63: 2-6.

5. Italian Medicines Agency (Agenzia Italiana del Farmaco-AIFA) (2009) the use of medicines in Italy-National Report-Year (2008) Pensiero Scientifico Editore, Rome, Italy.

6. Waltham MS (1998) Roadmaps to Market: Commercializing Functional Foods and Nutraceuticals, Decision Resources Inc 5
7. Brookes G (2010) Economic Impact Assessment of the European Union (EU)'s Nutrition and Health Claims Regulation on the EU food supplement sector and market, for the European Health Claims Alliance (EHCA)

8. Clydesdale FM (1997) A proposal for the establishment of scientific criteria for health claims for functional foods. Nutr Rev 55: 413-422.

9. Nicoletti M, Petitto V (2010) Contamination of herbal products determined by NMR fingerprint. Nat Prod Res 24: 1325-1329.

10. Nicoletti M (2011) HPTLC fingerprint: a modern approach for the analytica determination of botanicals. Rev Bras Farmacogn. 21: 818-823.

11. Nicoletti M (2011) Identification of Thiosildenafil in a Health Supplement. Nat Prod Commun 6: 1003-1004.

12. Kanan SM, Abu-Yousef IA, Gunasekar C, Abdo N, Narasimhan S (2009) Detection and Quantification of Synthetic Drugs in Herbal Slimming Formula. European Journal of Scientific Research 34: 348-357.

13. Henry P (1982) Gemmothérapie. Therapeutic plant extracts embryonic. B Westerlo, Impr. Saint Norbert.

14. Pharmacopéè Francaise (1965) (7thedn) Wolter Kluver France

15. Reich E, Schibli A (2006) A High-performance thin-layer chromatography for the analysis of medicinal plants. Thieme Medical Publishers Inc.

16. Reich E, Widmer V (2009) Plant Analysis 2008-Planar Chromatography. Planta Med 75: 711-718.

17. Gallo FR, Multari G, Federici E, Palazzino G, Giambenedetti M, et al. (2011) Chemical fingerprinting of Equisetum arvense L. using HPTLC densitometry and HPLC. Nat Prod Res 25: 1261-1270.

18. Piccin A, Toniolo C, Nicoletti M (2012) Analytical tools for digestive plant extracts Nutrifoods 11: 29-35.

19. Nicoletti M (2012) The Modern Analytical determination of Botanicals and Similar Novel Natural Products by HPTLC Fingerprint Approach in Studies on Natural Product Chemistry. Bioactive Natural Products. Atta-ir-Rahman (Edn) Elsevier 37: 217-258

20. Xie P, Chen S, Liang YZ, Wang X, Tian R, et al. (2006) Chromatographic fingerprint analysis-a rational approach for quality assessment of traditional Chinese Herbal medicine. J Chromatogr A 1112: 171-180.

21. TLC Atlas of Chinese Crude Drugs in Pharmacopoeia of the People's Republic of China (2009) Chinese Pharmacopoeia Commission. People's Medical Publishing House.

22. The United States Herbal Pharmacopoeia (31stedn) The National Formulary, (26thedn) Rockville: The United States Pharmacopoeia Convention.

23. World Health Organization (1998) Quality control methods for herbal materials WHO Library Cataloguing: Geneva.

Submit your next manuscript and get advantages of OMICS Group submissions

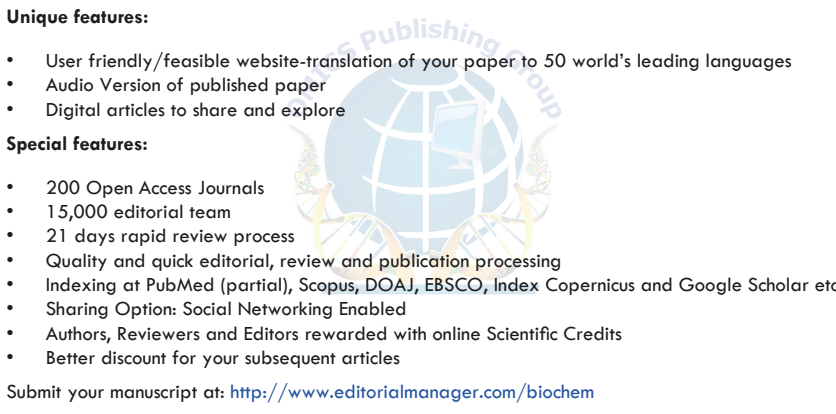

